\title{
Is prophylaxis for osteoporosis indicated after acute spinal cord injury?
}

\author{
Yannis Dionyssiotis ${ }^{1}{ }^{1}$
}

Received: 30 November 2018 / Revised: 25 December 2018 / Accepted: 28 December 2018

(c) International Spinal Cord Society 2019

\begin{abstract}
Spinal cord injury (SCI)-related osteoporosis is common complication in people with tetraplegia or paraplegia. Studies have shown that sublesional regions are severely demineralized. Loss of bone and sequential fractures are major problems in people with SCI that lead to further immobilization and decreasing quality of life. Despite extensive research mechanisms of this bone impairment are inadequately understood. This article discusses basics of bone metabolism physiopathology along with pharmaceutical prevention and treatment approaches to manage acute SCI-related bone loss.
\end{abstract}

Traumatic SCI results in various degrees of osteoporosis below the level of injury. However, the loss of mechanical stimuli due to paralysis during the acute phase is the main reason for SCI-related bone loss and not immobilization [1-3]. An intensive demineralization occurs immediately after injury which is more intensive in comparison to conditions like ageing, bed rest-related immobility and lack of gravity [4]. In the first 6 months post SCI bone is lost at a rate of $4 \%$ and $2 \%$ each month, in affected trabecular and cortical bone sites, respectively. This process tends to stabilize after 12 months $[5,6]$.

The activity of osteoclasts is ten times higher compared to normal and can be observed 10 weeks after injury. An uncoupling during bone remodelling occurs; formation initially decreases while resorption is steadily increased [7].

Calcium overload exceeds the normal regulatory mechanism of the body and this results in hypercalciuria and hypercalcemia. Hypercalciuria occurs within 10 days after injury, and plateaus between the first and $6^{\text {th }}$ month, with values 2-4 times higher compared with long-term bed immobilization. Moreover, hypercalcaemia usually occurs in 4-8 weeks but may begin as early as 2 weeks or 6 months after the injury. If not treated, complications, such as dehydration, personality changes, calcium nephrolithiasis,

Yannis Dionyssiotis

dionyssiotis@gmail.com

1 Physical Medicine and Rehabilitation Clinic, General University Hospital of Ioannina, Ioannina, Greece and renal insufficiency may occur. Early mobilization and hydration may reverse the disturbed equilibrium of calcium excretion and absorption [8,9].

In acute SCI, calcium intake is beneficial because parathormone (PTH) is suppressed. The suppression of PTH results in reduced absorption of calcium in gut. However, other medical specialties highlight the risk of calcium nephrolithiasis after the acute SCI due to high bone turnover and may misguide people with SCI to avoid calcium intake or dairy products [10].

In addition low calcium level provokes production of PTH to produce more $1,25(\mathrm{OH}) 2 \mathrm{D}$. Increased values of PTH initiate bone remodelling, resulting in further bone resorption and increasing released calcium ions in the blood. Before starting therapy with antiresorptive drugs supplementation with vitamin $\mathrm{D}$ is necessary. If $25(\mathrm{OH}) \mathrm{D}$ levels are below normal, calcium is inadequately absorbed in gut and because an antiresorptive agent like bisphosphonates or denosumab strongly suppresses bone resorption, severe iatrogenic hypocalcaemia may develop [11].

In acute phase of SCI normalization of bone metabolism indices and prevention of bone resorption has been attempted mostly with either oral or intravenous bisphosphonates. To lower serum calcium in people with SCI who suffer from immobilized related hypercalcemia the combined use of etidronate and calcitonin [12] as well as zoledronic acid and pamidronate have been used, however zoledronic acid was more effectively [13]. As the patient improves, the co-administration of intravenous saline solution (with or without furosemide) with pamidronate increases efficacy. In hypercalcaemic values, calcitonin may 
be used initially, until the action of pamidronate has begun [14].

Continuous intravenous (i.v.) pamidronate in the early phase of injury reduced the rate of bone loss, as revealed by urine N-terminal telopeptide (NTx) and 24-h urine calcium values, and bone mineral density (BMD) reduction rates. However, this only occurred with administration during the first months post SCI and longer-term inefficacy may be related to the time post-SCI that pamidronate was administrated. Timely administration of the drug could enhance its efficacy. Another reason for the lack of longer action may be that it was not accompanied by mechanical stimuli in the bone [15].

In people with acute SCI unloading causes higher sclerostin levels compared to the able-bodied and is associated with reduced bone formation during the initial phase. Recent findings suggest sclerostin may have great potential as a target in preventing bone loss after acute SCI. Walking ability hampers the increases in sclerostin level and modulating the bone's response to a lack of mechanical forces, may partially protective. Reduction of sclerostin levels and promotion of bone formation may be possible during the first 6 months post SCI. On the contrary, treatment with an anti-sclerostin antibody in chronic SCI would be ineffective. However, these recent physiopathological findings need confirmation in longitudinal studies of people with acute SCI [16].

Administration of oral etidronate $800 \mathrm{mg} / \mathrm{day}$ and calcium $1000 \mathrm{mg} /$ day via dietary intake in 2 cycles for 2 weeks, with a 13-week difference, 6 weeks after injury, maintained bone mineral density over a 12-month period in a subgroup of incomplete SCI individuals who became ambulatory within 3 months post SCI [17]. In another study administration of i.v. pamidronate in people with SCI during the first 6 months post SCI resulted in significantly less BMD loss compared with those who did not receive pamidronate. Mean loss of BMD was 3.1 and 7.7\%, in AIS D and AIS A group, respectively. Combined treatment with ambulation and pamidronate preserved best BMD values [18].

A prospective open label randomized study documented the effects of daily $10 \mathrm{mg}$ alendronate plus $500 \mathrm{mg}$ elemental calcium compared to $500 \mathrm{mg}$ elemental calcium alone, in preventing tibial trabecular and cortical bone loss in men with complete paraplegia. However, the effects were not significantly in the acute phase, but only over 24 months [19]. Others, using tiludronate $400 \mathrm{mg} / \mathrm{day}$ for 3 months in the acute post-SCI phase observed through bone biopsy in paraplegics a non-significant increase and reduction of bone resorption [20].

Three randomized control trials addressed efficacy of zoledronic acid to prevent BMD loss in acute SCI and found that i.v. infusion of zoledronic acid $(4-5 \mathrm{mg})$ once per year results reduces loss of bone in the hip and proximal femur in a 12-month period [21-23]. In the acute phase i.v. administration of bisphosphonate is potentially advantageous. People with SCI must stand upright at swallowing for almost $60 \mathrm{~min}$ after taking the pill when oral bisphosphonates are chosen for treatment, which may not be possible for some. In addition, cervical lesions may suffer from dysphagia and it may is not safe to swallow [21].

Finally, an ongoing prospective observational study found an increase of BMD in spine and femur 1 year after initiating therapy with early administration of denosumab. Therefore, denosumab may be an alternative in the future against osteoporosis in people with SCI [24].

Factors such as small numbers of subjects, heterogeneity of level of injury, AIS scale, drug interventions, outcomes and duration of follow-ups, increase the risk of bias and cause difficulties to understand the results and make the proper recommendations for pharmacological therapy.

In conclusion, based on current data antiresorptive therapy alone has a limited effect on complete lesions. However, this is not the case for incomplete subjects. The combination of reduced osteoclastic activity, using bisphosphonates early after injury and controlling calcium metabolism, together with the osteoblastic activity from a rehabilitation program, including walking, limits bone loss and retains bone density. The drug selection, dosage and the most appropriate time of administration are related and need to be investigated in future studies.

\section{Compliance with ethical standards}

Conflict of Interest The author declares no financial interest in relation to the work described.

Publisher's note: Springer Nature remains neutral with regard to jurisdictional claims in published maps and institutional affiliations.

\section{References}

1. Garland DE, Adkins RH, Stewart CA. Bone Impairment and Spinal Cord Injury. In: Stone JH, Blouin M, editors. International Encyclopedia of Rehabilitation; 2013. http://cirrie.buffalo.edu/ encyclopedia/en/article/108/.

2. Dionyssiotis Y. Spinal cord injury-related bone impairment and fractures: an update on epidemiology and physiopathological mechanisms. J Musculoskelet Neuron Interact. 2011;11:257-65.

3. Schiessl H, Ferretti JL, Tysarczyk-Niemeyer G, Willnecker J. The role of the muscles to the mechanical adaptation of bone. In: Lyritis GP, (ed). Advances in osteoporosis, vol.1. Athens: Hylonome Editions; 1998. p. 63-71.

4. Maimoun L, Fattal C, Micallef JP, Peruchon E, Rabischong P. Bone loss in spinal cord-injured patients: from physiopathology to therapy. Spinal Cord. 2006;44:203-10.

5. Soleyman-Jahi S, Yousefian A, Maheronnaghsh R, Shokraneh F, Zadegan SA, Soltani A, et al. Evidence-based prevention and treatment of osteoporosis after spinal cord injury: a systematic review. Eur Spine J. 2018;27:1798-14. 
6. Wilmet E, Ismail AA, Heilporn A, Welraeds D, Bergmann. Longitudinal study of the bone mineral content and of soft tissue composition after spinal cord injury. Paraplegia. 1995;33:674-7.

7. Uebelhart D, Demiaux-Domenech B, Roth M, Chantraine A. Bone metabolism in spinal cord injured individuals and in others who have prolonged immobilisation. A review. Paraplegia. 1995;33:669-73.

8. Elias AN, Gwinup G. Immobilization osteoporosis in paraplegia. J Am Paraplegia Soc. 1992;15:163-70.

9. Bauman WA, Garland DE, Schwartz E. Calcium metabolism and osteoporosis in individuals with spinal cord injury. Top Spinal Cord Inj Rehabil. 1997;2:84-96.

10. Naftchi NE, Viau AT, Sell GH, Lowman EW. Mineral metabolism in spinal cordinju ry. Arch Phys Med Rehabil. 1980;61:139-42.

11. Bauman WA, Cardozo CP. Osteoporosis in individuals with spinal cord injury. PMR. 2015;7:188-201.

12. Meythaler JM, Tuel SM, Cross LL. Successful treatment of immobilization hypercalcemia using calcitonin and etidronate. Arch Phys Med Rehabil. 1993;74:316-9.

13. Major P, Lortholary A, Hon J, et al. Zoledronic acid is superior to pamidronate in the treatment of hypercalcemia of malignancy: a pooled analysis of two randomized, controlled clinical trials. J Clin Oncol. 2001;19:558-67.

14. Maynard FM. Immobilization hypercalcemia following spinal cord injury. Arch Phys Med Rehabil. 1986;67:41-4.

15. Bauman WA, Wecht JM, Kirshblum S, Spungen AM, Morrison $\mathrm{N}$, Cirnigliaro $\mathrm{C}$, et al. Effect of pamidronate administration on bone in patients with acute spinal cord injury. J Rehabil Res Dev. 2005;42:305-13.
16. Battaglino RA, Lazzari AA, Garshick E, Morse LR. Spinal cord injury-induced osteoporosis: pathogenesis and emerging therapies. Curr Osteoporos Rep. 2012;10:278-85.

17. Pearson EG, Nance PW, Leslie WD, Ludwig S. Cyclical etidronate: its effect on bone density in patients with acute spinal cord injury. Arch Phys Med Rehabil. 1997;78:269-72.

18. Nance PW, Schryvers O, Leslie W, Ludwig S, Krahn J, Uebelhart D. Intravenous pamidronate attenuates bone density loss after acute spinal cord injury. Arch Phys Med Rehabil. 1999;80:243-51.

19. Zehnder Y, Risi S, Michel D, Knecht H, Perrelet R, Kraenzlin M, et al. Prevention of bone loss in paraplegics over 2 years with alendronate. J Bone Miner Res. 2004;19:1067-74.

20. Chappard D, Minaire P, Privat C, Berard E, MendozaSarmiento J, Tournebise $\mathrm{H}$, et al. Effects of tiludronate on bone loss in paraplegic patients. J Bone Miner Res. 1995;10:112-18.

21. Bubbear JS, Gall A, Middleton FR, Ferguson-Pell M, Swaminathan R, Keen RW. Early treatment with zoledronic acid prevents bone loss at the hip following acute spinal cord injury. Osteoporos Int. 2011;22:271-9.

22. Shapiro J, Smith B, Beck T, Ballard P, Dapthary M, BrintzenhofeSzoc K, et al. Treatment with zoledronic acid ameliorates negative geometric changes in the proximal femur following acute spinal cord injury. Calcif Tissue Int. 2007;80:316-22.

23. Schnitzer TJ, Kim K, Marks J, Yeasted R, Simonian N, Chen D. Zoledronic acid treatment after acute spinal cord injury: results of a randomized, placebo-controlled pilot. Trial PMR. 2016;8:833-43.

24. Gifre L, Vidal J, Carrasco JL, Muxi A, Portell E, Monegal A, et al. Denosumab increases sublesional bone mass in osteoporotic individuals with recent spinal cord injury. Osteoporos Int. 2016;27:405-10. 